This is a post-peer-review, pre-copyedit version of an article published in Advanced Materials Research. The final authenticated version is available online at: https://doi.org/10.4028/www.scientific.net/AMR.1018.441

\title{
3D Printing of Inorganic Sand Moulds for Casting Applications
}

\author{
Robert Ramakrishnan ${ }^{1, a}$, Benjamin Griebel ${ }^{1, b}$, Wolfram Volk ${ }^{1, c}$, \\ Daniel Günther ${ }^{2, \mathrm{~d}}$ and Johannes Günther ${ }^{2, \mathrm{e}}$ \\ ${ }^{1}$ Technische Universität München - Institute of Metal Forming and Casting (utg), \\ Walther-Meißner-Straße 4, 85748 Garching, Germany \\ ${ }^{2}$ voxeljet AG, Paul-Lenz-Straße 1, 86316 Friedberg, Germany \\ arr@utg.de, bbg@utg.de, 'cwv@utg.de, ddg@voxeljet.de ejfg@voxeljet.de
}

\section{Keywords: Casting, Rapid Prototyping, Sand Mould}

\begin{abstract}
The paper at hand introduces a 3D printing (3DP) process for additive manufacturing of inorganically bound sand moulds. The fundamental differences to 3DP with organic binders (which is state of the art) are explained and the quality relevant process parameters of the inorganic process are introduced. Since the inorganic binder system is thermally activated during the printing process the main focus lies on the heating procedure. The properties of printed specimens are measured by the quality features fluid migration and strength for which novel methods of moulding sand testing are used. Results show that the identified process parameters have a significant influence on specimen properties. The interaction of the attributes fluid migration and strength are also shown. By understanding the relationship between process parameters and quality features the properties of printed inorganic sand moulds can be tailored to fit casting specific requirements.
\end{abstract}

\section{Introduction}

Stronger ecological awareness of society and the connected political pressure on the manufacturing industry have led to a strong trend among German and European foundries in the last 10 years: The number of foundries shifting their production of sand moulds and cores from organic to inorganic binder systems is growing rapidly [1]. These inorganic binders contain none or very little hydrocarbons [2]. This leads to a massive reduction of harmful emissions when hot metallic melts come in contact with the bound sand [3]. Further technological and economic advantages e.g. reduction of tool contamination and savings in air exhaustion systems motivate foundries to invest in process modifications in favour of inorganic binders [4]. Primarily inorganic binders are being used for core blowing. The sand-binder mixture is fluidized by air pressure and blown into a heated core box where curing takes place by dehydration [5]. However a shift from organically to inorganically bound sand moulds and cores is a profound change in the production process of a cast part. A rapid prototyping (RP) process which works with similar inorganic binder systems could ensure feasibility and quality of a cast part in a very early stage of product design. The development of such an additive 3DP process working with inorganic binders is the scope of the presented research project of the Lehrstuhl für Umformtechnik und Gießereiwesen, Garching in association with voxeljet technology AG, Friedberg. Additive manufacturing is especially interesting for the production of prototypes or small batches since this production method is not dependant on costly core making tools. The state of the art in 3DP for foundry applications is based on organic binders [6]. These binders often contain harmful and toxic substances [7]. Furthermore the properties, e.g. core gassing during casting, of an organically printed core cannot be transferred to a core which is manufactured by core blowing with inorganic binders [8]. Our research concentrates on the cause and effect relationship of process parameters and quality features. This article describes the process characteristics of 3DP with 
inorganically bound moulding sands and shows results for selected properties of the printed specimens.

\section{Basics}

3DP of Moulding Sands for Casting Applications. Among the large number of rapid prototyping processes the article at hand relates to "indirect 3D Printing (3DP)" as defined by the VDI-Richtlinie 3404. In agreement with this definition this is an "additive technique in which an adhesive is deposited dot by dot onto a powder bed, causing the powder to bond where the adhesive is deposited" [9]. Of all RP processes 3DP of sand moulds and cores is the one which is the most meaningful for industrial casting applications [10]. Fuelled by rising complexity and diversity of cast parts 3DP is also becoming interesting for mass production applications [11]. 3DP enables the manufacturing of a ready-to-cast mould directly from $\mathrm{CAD}$ data. Figure 1 schematically illustrates the single 3DP process steps.

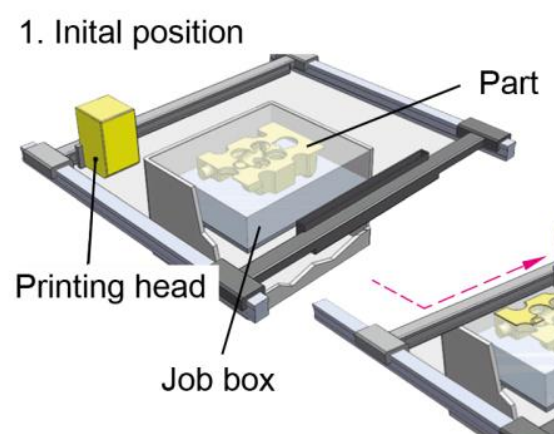

2. Printing

\section{Lowering and retreat}

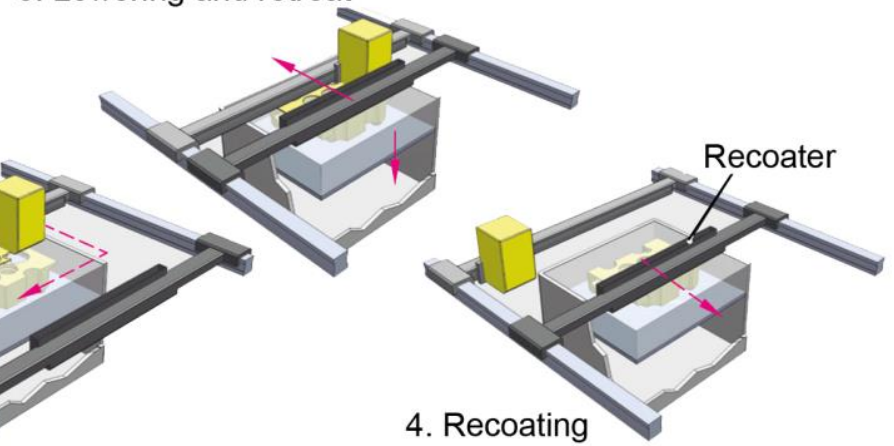

Figure 1: 3DP process steps [12]

Appropriate software slices the parts CAD data into single layers and transfers them to the 3D printer. Every layer cycle consists of recoating a thin layer (approx. $250 \mu \mathrm{m}$ ) of particle material, selectively printing the slice and lowering of the jobbox base plate by the slice height. By repeating this cycle many times a sand mould can be produced which must merely be freed from loose sand prior to casting.

Binder Systems for 3DP and Basics of Thermal Processing. The voxeljet VX-500 3D printing system this research is based on was originally designed to process polymer powders. By modifying the printer material handling and fluid system basic processability of the inorganic sand binder system (SBS) could be achieved. In order to reach the desired mould material properties thermal processing during the printing process is necessary. This is the main difference compared to the state of the art process which works with organic furanic resins. Figure 2 shows the single steps of the binder reaction in an organic and an inorganic printing process. 


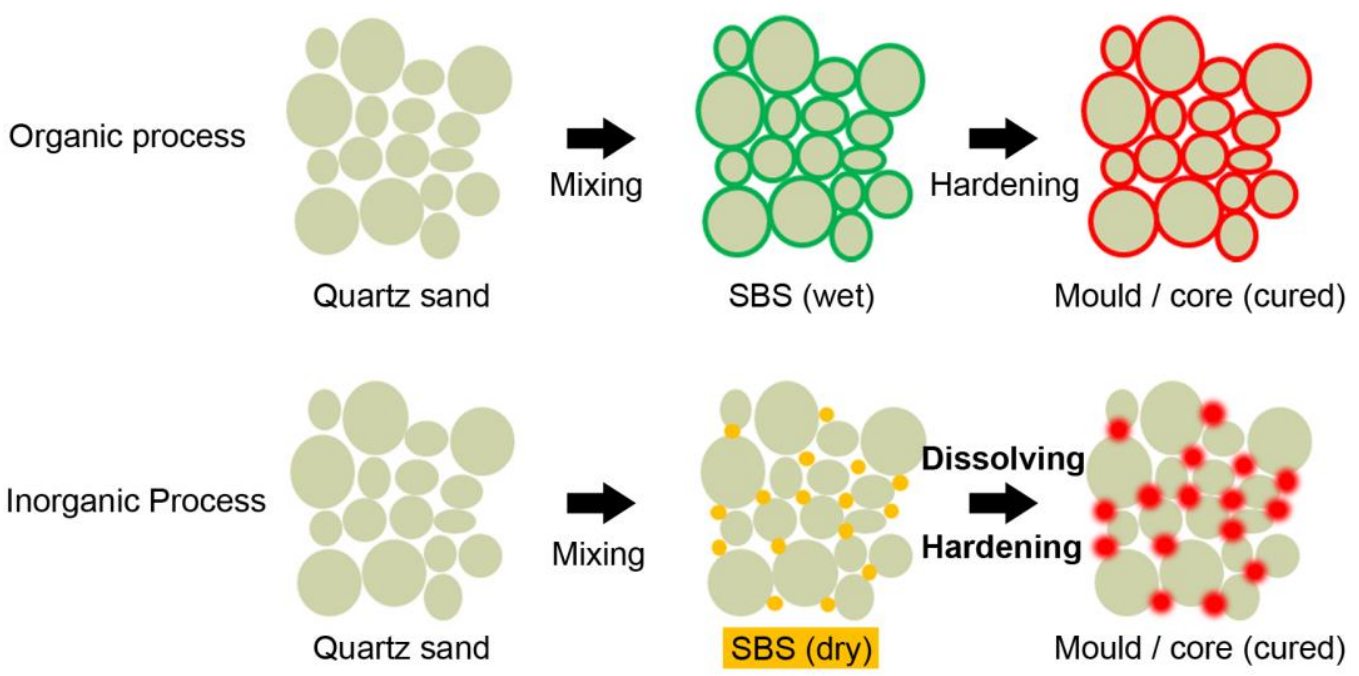

Figure 2: Schematic comparison of the binder reaction during the 3D printing process with an organic and an inorganic binder system

Initially quartz sand is mixed with the binder. In the organic process this is done by combining the sand with one of the binder components (resin or curing agent) prior to the printing process. The wetted sand mixture is spread inside the jobbox by the recoater. The printing head dispenses droplets of the second binder component. Where it comes in contact with the sand mixture the hardening reaction takes place instantaneously. In case of the inorganic process quartz sand is mixed with a dry sodium silicate powder which functions as binder. Recoating is done in the same manner as in the organic process. In this case the printing fluid consist of thickened water which is able to dissolve the sodium silicate. Figure 3 illustrates the single steps of the reaction.

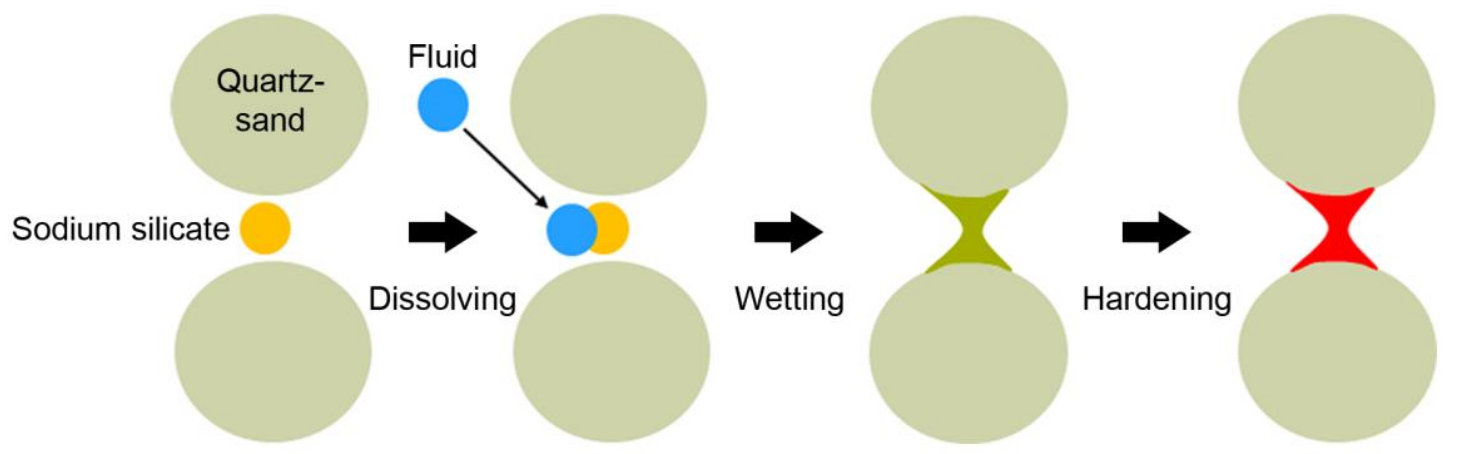

Figure 3: Single steps of dissolving, wetting and hardening of the inorganic binder

The sodium silicate binder between the sand particles is dissolved by water which is dispensed by the printing head. The viscous binder can wet the surrounding sand and form binder bridges which can be hardened by physical dehydration [13]. The characteristics of the dissolving and hardening processes significantly influence the properties of the printed parts. In order to tailor these properties different process parameters of the 3DP process can be varied, which are described in the following section.

\section{Experimental}

Setup and Process Monitoring. Based on the inorganic binder reaction described before the two main parameters concentration ratio (sodium silicate / water) and activation energy (heat) shall be of further interest. The amount of sodium silicate in the sand mixture is constant at $10 \mathrm{wt}$. \%. By changing the amount of fluid per voxel (input) the concentration ratio can be varied. The input $I_{F l}$ in per cent [\%] can be calculated by equation 1 : 


$$
I_{F l}=\frac{m_{F l}}{\rho_{S B S} \cdot d x \cdot d y \cdot d z}
$$

By measuring the fluid mass $m_{F l}$ as well as the SBS density $\rho_{S B S}$ and setting the voxel size $(d x \cdot d y \cdot d z)$ the input can be determined. The second main parameter - activation energy - can be varied by heating the SBS during the process. Thermal processing hereby controls binder activation (dissolution) and hardening (dehydration). Heating is realized by a controllable infrared (IR) emitter which is mounted to the printing axis and can be guided parallel to the job box surface (see Figure 4(b)). The emitter power is controlled by a LabView ${ }^{\circledR}$ (National Instruments Germany GmbH) program which allows designated heating of the SBS during the printing process. An infrared camera (IRC) which is mounted above the job box can record full-radiometric images which give us the possibility to thermally monitor the process. Figure 4 shows photographs of the 3D printer with the mounted IRC and an inside view during printing.

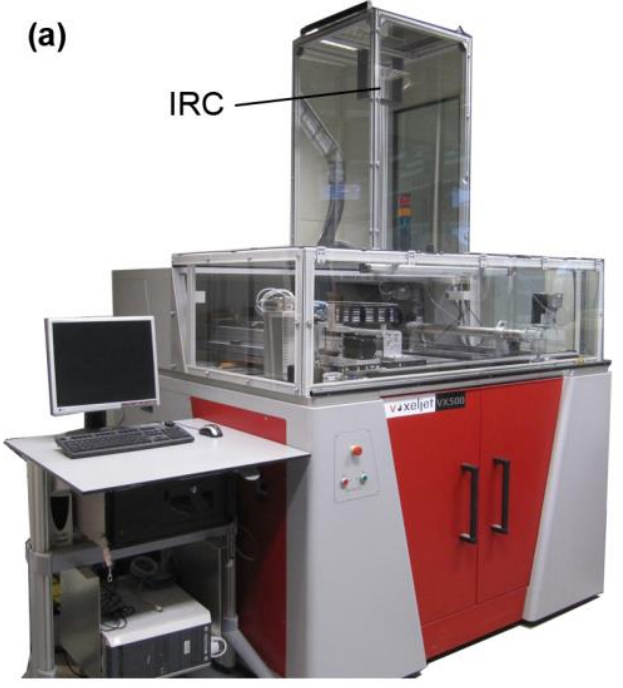

(b)

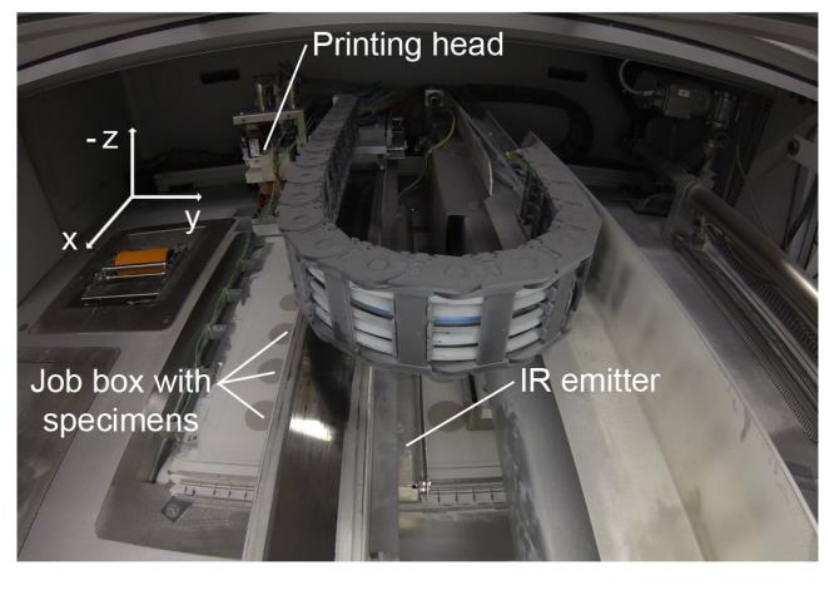

Figure 4: External view (a) of the 3D printer VX 500 an internal view (b) during the printing process

Besides the main parameters mentioned earlier a series of other factors can influence the properties of 3D printed parts. E.g. sand specifications, compression, part position an orientation must be accounted for [14]. These factors are held constant for the experiments published here.

Quality Features and Specimens. In order to determine effects of the varied process parameters relevant quality features must be defined. The selection of these features is based on the VDIRichtlinie 3404 as well as on VDG-Merkblatt P38 [15] and P72 [16] for testing of moulding sand and binder properties. Depending on these guidelines specimen geometries were defined which can be used to quantify the main quality features fluid migration and strength. Fluid migration describes the penetration of fluid from printed into non-printed areas. It is caused by the SBS affinity to water which pulls a droplet of fluid into all directions once in contact with the sand mixture. Fluid migration results in undesired sand adhesion and therefore poor dimensional accuracy. The specimen which is used for quantifying fluid migration is shown in Figure 5. 
(a)

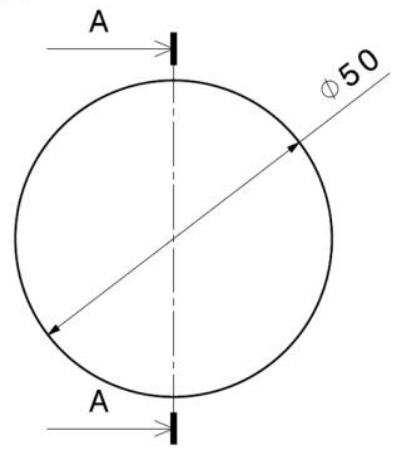

(b)

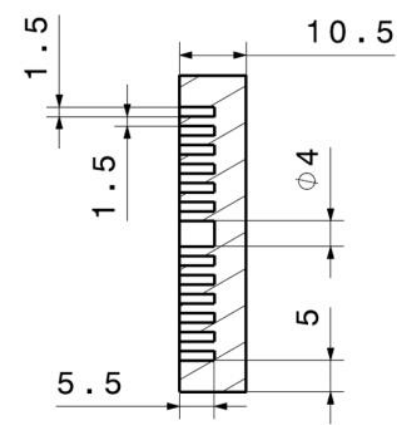

(c)

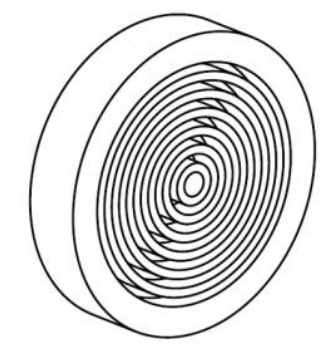

Figure 5: Front view (a), section A-A (b) and isometric view (c) of fluid migration specimen

This specimen is critical for fluid migration since it combines massive and delicate areas. Depending on the severeness of fluid migration sand adhesion takes place between the thin walls. This leads to higher specimen weight which can be easily measured. Fluid migration is specified in per cent and standardised to an ideal specimen weight of $20 \mathrm{~g}$. Accordingly $0 \%$ fluid migration stands for a specimen with no fluid migration. From the additive manufacturing as well as from sand testing point of view strength is a crucial property. Guidelines from both areas propose a wide range of methods for strength testing e.g. compression [15], bending [16] or tensile tests [9]. Since specimen properties can vary depending on their position inside the job box relatively small testing geometries are favourable since a larger number can be positioned inside a given space. A testing method which complies with these requirements is the ball on three balls $(B 3 B)$ test invented by Danzer et al. [17]. It requires specimens of a disc geometry which have a certain diameter to thickness ratio. According to VDG-Merkblatt P38 we chose a specimen of $50 \mathrm{~mm}$ diameter and $10 \mathrm{~mm}$ thickness. To ensure accurate specimen thickness we print an oversize of $0.5 \mathrm{~mm}$ and finish the specimens in a steel gauge to an allowance of $+/-0.1 \mathrm{~mm}$. Testing takes place in a Zwick Z020 testing machine. As shown in Figure 6 the specimen is positioned between three bearing steel balls and one loading steel ball.

(a)

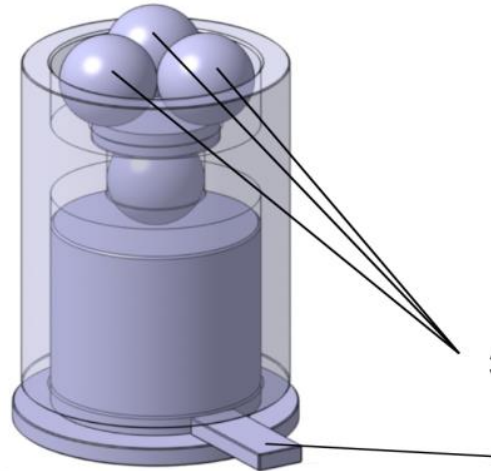

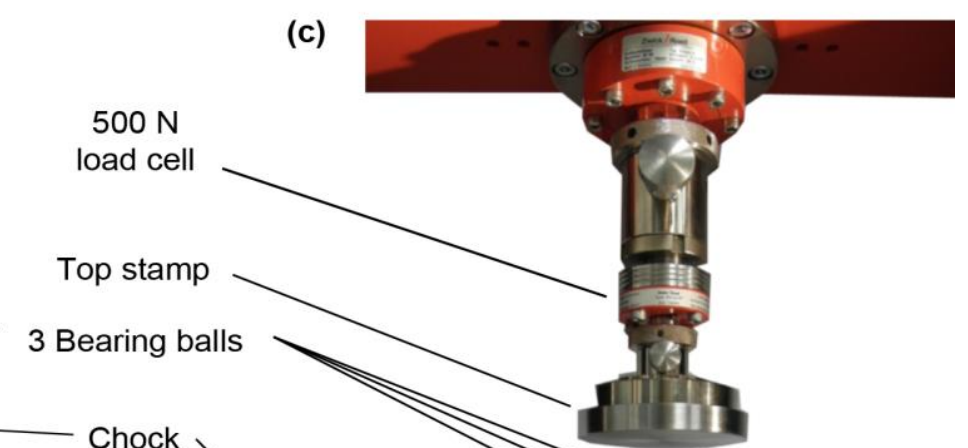

(b)

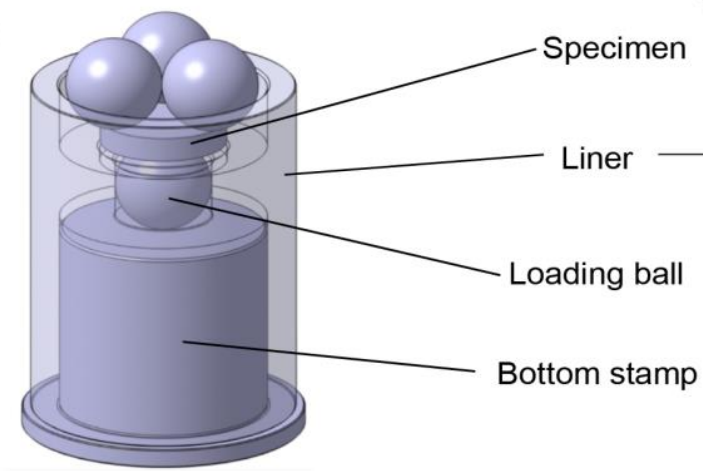

Figure 6: CAD model of the B3B setup with inserted chock (a) and without the chock (b) as well as the real setup inside of the Z020 testing machine (c)

Part (a) of the figure shows the CAD model of the testing setup where the specimen is centred by the liner prior to testing. A starting load of $50 \mathrm{~N}$ is applied to the specimen via the top and bottom 
stamp which pinches it between the 4 balls. Subsequently the chock can be pulled out and the liner is lowered as shown in part (b). Now the specimen is only fixed between 4 points and can be loaded with a feed rate of $1 \mathrm{~mm} / \mathrm{min}$ until fracture. Maximum tensile stresses appear in the specimen centre opposite to the loading ball. As a result fracture initiates in the centre of the specimen which makes this testing method insusceptible to edge effects [18]. Test validation can be easily performed by visual inspection as illustrated in Figure 7.

(a)

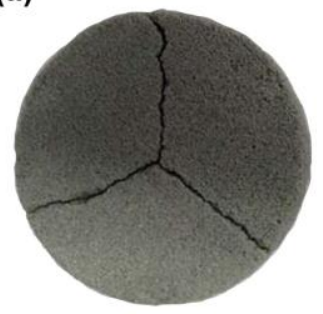

(b)

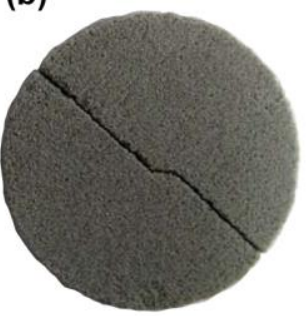

(c)

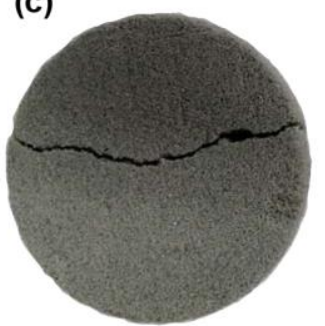

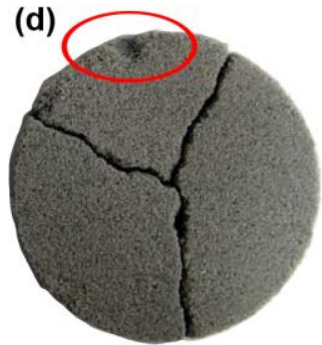

Figure 7: Comparison of fracture patterns of two valid specimens (a) and (b) and two invalid specimens with non-centred fracture (c) and edge breakout (d)

A valid specimens will show fracture through the centre and have no indications of edge breakouts. Specimen strength is characterised by the fracture stress $\sigma_{B 3 B}$ in $\left[\mathrm{N} / \mathrm{mm}^{2}\right]$ which can be calculated from the measured fracture load $F_{F}$ and the specimen thickness $t$ by the following equation [18]:

$$
\sigma_{B 3 B}=f \cdot \frac{F_{F}}{t^{2}}
$$

Based on a numerical simulation with ceramic materials the fit factor $f$ amounts to values between 1 and 3 depending on the material's Poisson ratio [18]. With a Poisson ratio for compacted sand of 0.3 [19] we can assume $f=1,56$ for the comparative results presented here. Due to the additive manufacturing process the specimens can be arranged freely inside the job box. Fig 8(a) shows a drawing of the standard specimen arrangement (SSA) inside the job box. The SSA is printed with the desired process parameters. After printing loose sand is blown off the specimens by defined air pressure and they are stored in a constant climate for 48 hours before testing.

\section{Results}

Thermal Process Analysis. With the IRC data we are able to analyse the thermal history of every single specimen during the printing process. Additionally to the SSA fig. 8 gives an example of two IR images which were taken during different printing processes. For thermal analysis an emission coefficient of $\varepsilon=1$ was assumed. Specimen numbering is defined by the position in $\mathrm{x}$ - and y-direction.

$z$ (a)

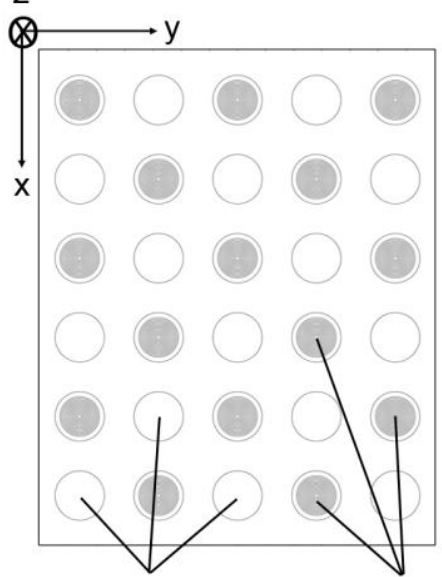

B3B specimens $z$ (b)

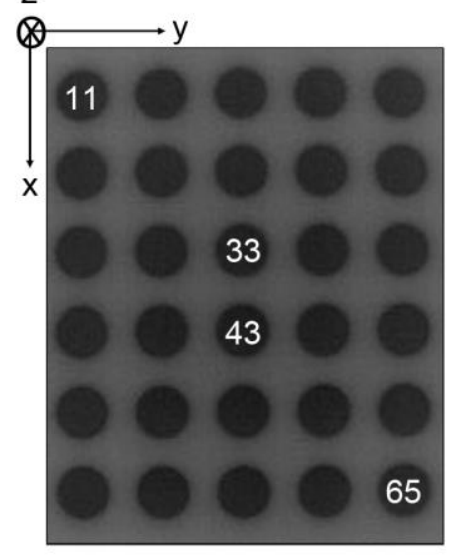

$z$ (c)

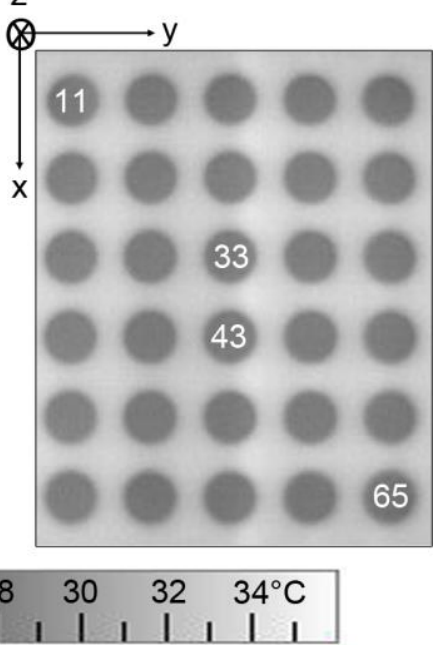

Figure 8: SSA (a) and comparison of two IR images shot during a printing process with deactivated (b) and activated (c) IR emitter 
The effect of infrared heating is clearly visible. By controlling the emitter power profile we can realize a homogeneous heat input into the job box surface. For quantitative comparison the fluid migration specimens \#11 and \#33 as well as the B3B specimens \#43 and \#65 are plotted in fig. 9(a).

(a)

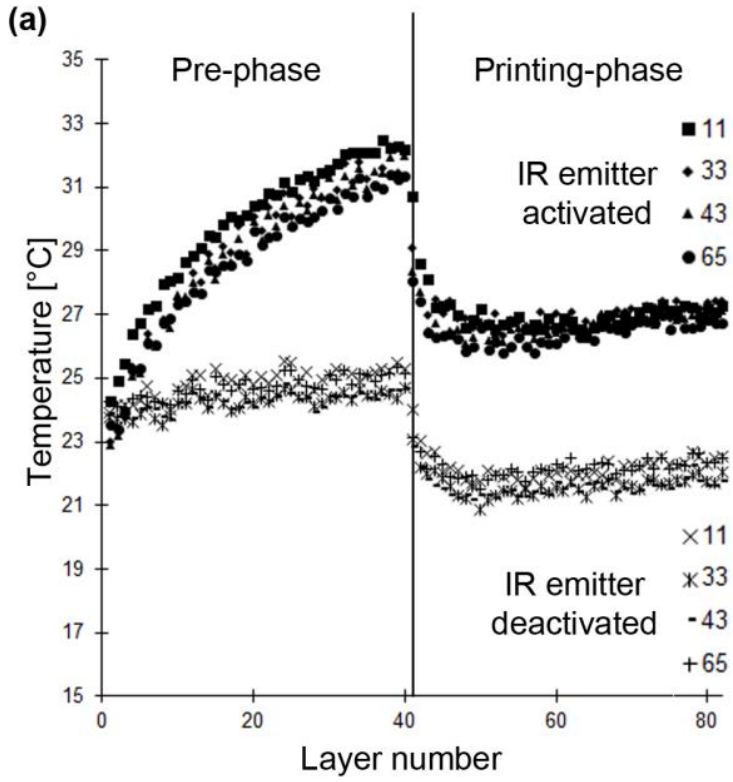

(b)

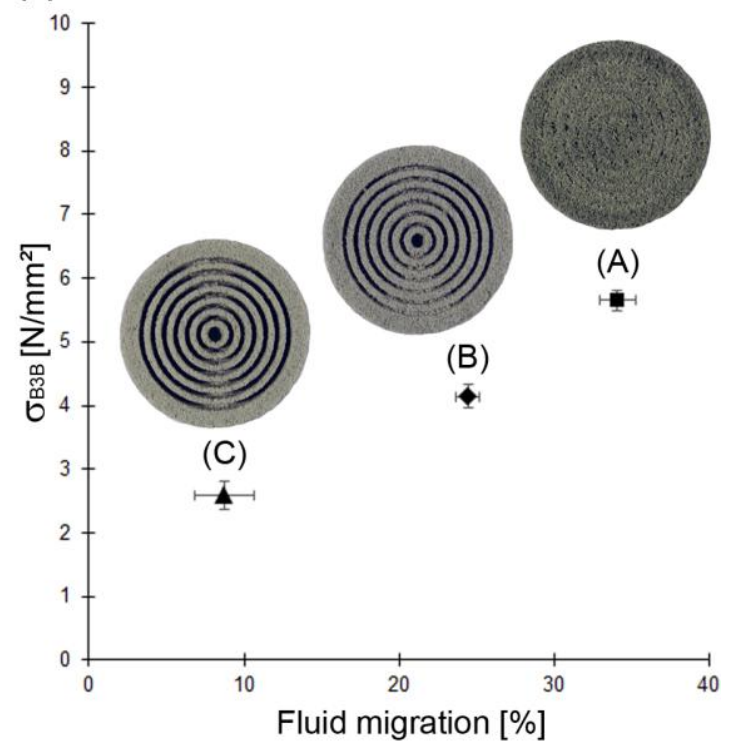

Figure 9: Surface temperature over layer number (a) and mean strength $\sigma_{\mathrm{B} 3 \mathrm{~B}}$ over mean fluid migration (b) for processes (A), (B) and (C) with fluid migration specimen examples

The SSA has a total height of $20.5 \mathrm{~mm}$ and consists of 82 layers. When the process starts the SBS is at room temperature. During the first 40 layers (pre-phase) no fluid is printed into the job box in order to reach stable thermal conditions. With an active IR emitter the surface temperature rises to approx. $30^{\circ} \mathrm{C}$. When specimen printing starts at layer 41 fluid is dispensed onto the job box which results in a clearly visible cooling of the surface. After a few layers surface temperatures balance to approx. $22^{\circ} \mathrm{C}$ for a deactivated and approx. $27^{\circ} \mathrm{C}$ for an active IR emitter. By controlling the emitter power these values can be held close to constant for the remaining printing process.

Quality Features. Depending on the process parameters concentration ratio and activation energy the defined quality features fluid migration and strength are analysed for the following three parameter sets:
(A) $8 \%$ fluid input, IR emitter off
(B) $8 \%$ fluid input, IR emitter on
(C) $5 \%$ fluid input, IR emitter off

The interaction of the attributes fluid migration and strength is shown in fig 9(b). It also illustrates the way fluid migration leads to sand adhesion inside the specimen. In all three processes a relatively homogenous distribution of fluid migration and strength with respect to the specimens' position in the job box could be achieved. The variation is represented by the corresponding standard deviation error bars. The effects of induced heat by the IR emitter can be seen when comparing processes (A) and (B). Without thermal activation mean fluid migration amounts to $34 \%$. By heating the specimens during printing this value can be reduced to $24 \%$. Fluid migration can also be limited by reducing the fluid input into the SBS. As can be seen in process (C) a reduction of input from $8 \%$ to $5 \%$ results is a mean fluid migration of $9 \%$. With respect to their mean strength, specimens manufactured in process (A) reveal the highest value of $5.65 \mathrm{~N} / \mathrm{mm}^{2}$. Heating during the printing process leads to a loss of strength resulting in a mean value of $4.14 \mathrm{~N} / \mathrm{mm}^{2}$ for process (B). When fluid input is lowered from $8 \%$ to $5 \%$ as done in process (C) we can observe a strong decrease in strength to a mean value of 2.59 $\mathrm{N} / \mathrm{mm}^{2}$. An increase in fluid migration leads to higher strength of the specimens. Thus printed parts which can sustain high mechanical loads have poor dimensional accuracy due to sand adhesion 
between the thin specimen walls. The presented results confirm that the identified and varied process parameters have a significant and controllable influence on the analysed quality features.

\section{Conclusions and Outlook}

The application of 3D printed cores and moulds is state of the art for casting prototypes and small batches. Organic furanic resins are conventionally used which have many ecological disadvantages. The experiments and results presented in this paper describe a 3DP process which is based on an ecofriendly, inorganic sodium silicate binder system. Investigations focus on the process parameters concentration ratio and activation energy. In order to describe the properties of the printed parts the quality features fluid migration and strength - measured in the B3B test - are introduced. We are able to show that sensitive process parameters have a distinct influence on the attributes of the printed specimens. This gives us a well-founded basis for further investigations in which the process parameters will be varied on the basis of design of experiments. More parameters, such as the process cycle time, will be taken into account and also the range of analysed properties will be extended. Future research will also be dedicated to the analysis of mould material data such as Young's modulus and Poisson ratio which make stress calculation for the 3B3 loading situation more reliable.

\section{Acknowledgements}

The authors would like to thank the Deutsche Bundesstiftung Umwelt (DBU) for providing financial support for the research project (DBU Aktenzeichen 30340 - 21/2/02) on which the presented work is based on.

\section{References}

[1] W. Tilch; H. Polzin, GIFA 2003: Formstoffe, Formverfahren und Maschinen zur Form- und Kernherstellung, Formstoffaufbereitung und Regenerierung. Giesserei-Praxis (2003) 407-429.

[2] H. Polzin, Übersicht chemisch härtende Formstoffe, Giesserei-Praxis (2007) 334-357.

[3] P. Groening, Formverfahren mit nicht tongebundenen Formstoffen, Giesserei 99 (2012) 34-43.

[4] T. Pabel, Anorganisches Bindersystem: Einsatz von INOTEC-Kernen für deutlich verbesserte mechanische Eigenschaften von Al-Gussteilen, Giesserei-Praxis (2009) 359-366.

[5] H. Polzin, Anorganische Binder zur Form- und Kernherstellung in der Gießerei. first ed., Schiele \& Schön, Berlin, 2012.

[6] I. Ederer, Werkzeuglose Formherstellung mittels 3D-Drucktechnologie, Giesserei-Praxis (2004) 407-410.

[7] A. Psimenos, The new EU-Regulation on Classification, Labelling and Packaging of Substances and Mixtures on the Foundry Industry, Giesserei-Rundschau 58 (2011) 10-13.

[8] E. Weissenbek, J. Willimayer, J. Wolf, BMW-Leichtmetallgießerei setzt auf anorganische gebundene Kerne, Giesserei 95 (2008) 32-35.

[9] VDI-Richtlinie 3404, Generative Fertigungsverfahren Rapid-Technologien (Rapid Prototyping) Grundlagen, Begriffe, Qualitätskenngrößen, Liefervereinbarungen, Beuth, Berlin, 2009.

[10]R. Höchsmann, Wie das 3-D-Druckverfahren Gießereiprozesse revolutioniert. Giesserei 100 (2013) 66-68.

[11]J.M. Ségaud, Vision 2025 - 3D - Drucken von Kernen, Giesserei 101 (2014) 24-25.

[12]U. Berger, A. Hartmann, D. Schmid, Additive Fertigungsverfahren: Rapid Prototyping, Rapid Tooling, Rapid Manufacturing, first ed., Europa Lehrmittel, Haan-Gruiten, 2013. 
[13]C. Wallenhorst, Grundlagen zum Verständnis der anorganischen Kernfertigung, Giesserei-Praxis (2010) 181-184.

[14]B. Utela, D. Storti, R. Anderson, M. Ganter, A review of process development steps for new material systems in three dimensional printing (3DP), Journal of Manufacturing Processes 10 (2008) 96-104.

[15]VDG-Merkblatt: Prüfung von tongebundenen Formstoffen P38: Bestimmung der Festigkeit, VDG Akademie, Düsseldorf, 1997.

[16] VDG-Merkblatt: Bindemittelprüfung P72: Prüfung von kalthärtenden, kunstharzgebundenen feuchten Formstoffen mit Härterzusatz, VDG Akademie, Düsseldorf 1999.

[17]R. Danzer, T. Lube, P. Supancic; M. Damani, A. Boerger; R. Binder, Verfahren und Einrichtung zur Bestimmung der Bruchfestigkeit von spröden Werkstoffen, Patent No. AT 411714 B, 2002.

[18]R. Danzer, P. Supancic; W. Harrer, Der 4-Kugelversuch zur Ermittlung der biaxialen Biegefestigkeit spröder Werkstoffe, in: Kriegesmann, Technische Keramische Werkstoffe, HvB Verlag, Ellerau, 2009, pp 1-48.

[19]H. Gercek, Poisson's ratio values for rocks, International Journal of Rock Mechanics \& Mining Sciences 44 (2007) 1-13. 